\title{
County-level climate change information to support decision-making on working lands
}

\author{
Emile Elias $^{1}$ • T. Scott Schrader ${ }^{1}$ • John T. Abatzoglou ${ }^{2}$ • \\ Darren James ${ }^{1}$ - Mike Crimmins ${ }^{3}$ • Jeremy Weiss ${ }^{4}$. \\ Albert Rango ${ }^{1}$
}

Received: 28 April 2016 / Accepted: 17 July 2017 / Published online: 28 August 2017

(C) The Author(s) 2017. This article is an open access publication

\begin{abstract}
Farmers, ranchers, and forest landowners across the USA make weather- and climate-related management decisions at varying temporal and spatial scales, often with input from local experts like crop consultants and cooperative extension (CE) personnel. In order to provide additional guidance to such longer-term planning efforts, we developed a tool that
\end{abstract}

This article is part of a Special Issue on 'Vulnerability of Regional Forest and Agricultural Ecosystems to a Changing Climate (USDA Southwest Climate Hub)’ edited by David Gutzler and Connie Maxwell

Electronic supplementary material The online version of this article (doi:10.1007/s10584-017-2040-y) contains supplementary material, which is available to authorized users.

Emile Elias

emile.elias@ARS.USDA.GOV

T. Scott Schrader

schrader@nmsu.edu

John T. Abatzoglou

jabatzoglou@uidaho.edu

Darren James

dkj2@nmsu.edu

Mike Crimmins

crimmins@email.arizona.edu

Jeremy Weiss

jlweiss@email.arizona.edu

Albert Rango

albert.rango@ARS.USDA.gov

1 U.S. Department of Agriculture-Agricultural Research Service, Jornada Experimental Range, Las Cruces, NM, USA

2 Department of Geography, University of Idaho, Moscow, ID 83844, USA

3 Department of Soil, Water and Environmental Science, University of Arizona, Tucson, AZ 85721, USA

4 School of Natural Resources and the Environment, University of Arizona, Tucson, AZ 85721, USA 
shows statistically downscaled climate projections of temperature and precipitation consolidated to the county level for the contiguous US. Using the county as a fundamental mapping unit encourages the use of this information within existing institutional structures like CE and other U.S. Department of Agriculture (USDA) programs. A "quick-look" metric based on the spatial variability of climate within each county aids in the interpretation of county-level information. For instance, relatively higher spatial variability within a county indicates that more localized information should be used to support stakeholder planning. Changes in annual precipitation show a latitudinal dipole where increases are projected for much of the northern US while declines are projected for counties across the southern US. Seasonal shifts in countylevel precipitation are projected nationwide with declines most evident in summer months in most regions. Changes in the spatial variability of annual precipitation for most counties were less than $10 \mathrm{~mm}$, indicating fairly spatially homogenous midcentury precipitation changes at the county level. Annual and seasonal midcentury temperatures are projected to increase across the USA, with relatively low change in the spatial variability $\left(<0.3^{\circ} \mathrm{C}\right)$ of temperature across most counties. The utility of these data is shown for forage and almond applications, both indicating a potential decline in production in some future years, to illustrate use of countylevel seasonal projections in adaptation planning and decision-making.

Keywords Climate change $\cdot$ Decision-making $\cdot$ Agriculture $\cdot$ Forestry $\cdot$ Ranching $\cdot$ USDA climate hubs $\cdot$ Cooperative extension

\section{Introduction}

Impacts of climate change on agriculture include redistribution of water availability, changes in the thermal suitability for agricultural zones, and changes in erosion and crop productivity. Adaptation planning, such as considering alternate crops and management strategies, and conservation practices for nutrients, soil, and water resources can minimize the impacts of climate variability and change on the agricultural sector (Walthall et al. 2012). In general, crop productivity may decline in response to increases in temperature, but impacts vary among crop type and region (Walthall et al. 2012).

Farmers and ranchers frequently make decisions based upon changing weather conditions and longer-term climate projections may be helpful to sectoral planning. Rising temperatures are projected to have far-reaching impacts on the agricultural sector in the USA (Schauberger et al. 2017), especially in combination with decreased water availability (Anderson et al. 2015). The increased frequency, duration, and intensity of drought and heat waves may exacerbate livestock and crop stress, resulting in greater susceptibility to disease and pests that may have increased occurrences, higher intensities, and expanded ranges (Anyamba et al. 2014; Deryng et al. 2014; Walthall et al. 2012). Agriculturists cope within an expected range of conditions relative to their locations; however, increased temperatures will alter growing seasons with earlier starts and longer duration, more high-temperature days, and warmer winters with fewer nights below freezing. These climatic changes can produce both negative and positive effects, for example while warmer winters may reduce yields of chill-depended crops (Luedeling et al. 2009), they can also lengthen the growing season of other crops and expand the potential range of agricultural crops currently limited by short growing seasons or insufficient heat accumulation. Increasing atmospheric carbon dioxide $\left(\mathrm{CO}_{2}\right)$ can boost plant growth, thus in some regions, climate change could lead to enhanced productivity, especially 
in areas with limited precipitation. However, elevated $\mathrm{CO}_{2}$ can also disproportionately stimulate the growth of weed species that can also reduce grain and forage quality (Walthall et al. 2012). Impacts to the US agricultural sector are dependent upon actions taken to support regional and local adaptive management.

\subsection{USDA Regional Climate Hubs}

In February 2014, the USDA announced the formation of ten hubs across the nation to help farmers, ranchers, and foresters adapt to the effects of climatic change (Fig. 1). Climate Hub regions were created in part due to regional differences in weather patterns, agricultural production, and anticipated regional variation in climate change impacts to agriculture.

\subsection{Weather and climate data use in agriculture and forest management}

In the USA, Cooperative Extension Service (CES) is often the primary source for agricultural information (Cash 2001). CES was created over 100 years ago to serve as the interface between land grant universities and stakeholders. While CES provides valuable support and information through county agents across the country, farmers in certain regions may be more likely to seek information from private agricultural advisors and consultants than CES (Prokopy et al. 2015). Since private agricultural advisors and consultants typically trust CES as a source of information and can also serve as a conduit of climate change information to farmers, foresters, and ranchers, CES is both an important user of weather and climate information and supporter of many weather and climate sensitive sectors (Brugger and Crimmins 2014). Whether CES works directly with farmers, foresters, and ranchers or through advisors, CES

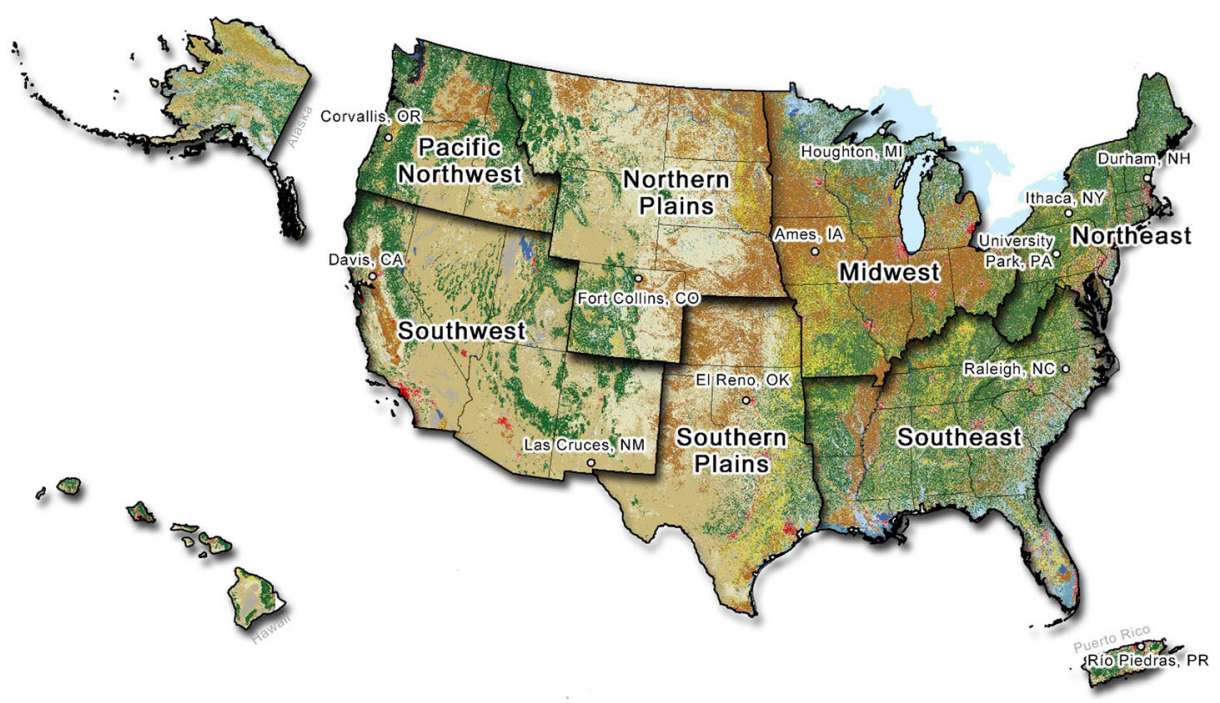

Fig. 1 The seven U.S. Department of Agriculture Climate Hub Regions, with subsidiary hubs located in Davis, California, Rio Piedras, Puerto Rico, and Houghton, Michigan. Hawaii and the USA-affiliated islands west are part of the Southwest Hub. Alaska is part of the Pacific Northwest Hub 
requires reputable weather and climate data for customers. The required data, however, depends upon the intended management actions as decisions are made with different time horizons. For example, foresters selecting trees adapted to midcentury temperatures require different information than farmers who are currently growing annual crops, or considering planting fruit or nut trees that might reach maturation in the next decade.

Incorporating weather information in agricultural management and planning has been shown to improve economic returns (Fuglie et al. 2007; Lazo et al. 2011; Solís and Letson 2013). On longer-term horizons, adaptive responses to climate change such as the selection of viable cropping systems would benefit from accessible temperature and precipitation information. Similarly, adaptive and informed forest management, such as assisted migration, will help build resilience in private and public forests (Duveneck and Scheller 2015; Williams and Dumroese 2013).

The impact of climate on crop yield prompted some of the first instrumented temperature measurements in the USA in 1731-1732 in Philadelphia (Fiebrich 2009). Today, weather is measured by a variety of networks and systems integrate data from over 10,000 stations, including volunteer observer networks, across the USA (Fiebrich 2009). These observations provide the foundation for understanding spatiotemporal variability of weather and climate, and are the primary basis for assessing climate variability and change. However, the observational climate network can suffer from inadequate station density, lack of long-term and continuous observations and quality control issues (Abatzoglou 2013; Menne et al. 2012). Gridded surface meteorological data have been developed by incorporating these observations with a variety of other considerations (e.g., topography, proximity to water) to provide spatially and temporally complete estimates (Abatzoglou 2013; Daly et al. 2008).

\subsection{Data to support county-level decision-making}

Support for agricultural decision-making is typically organized along political boundaries in the USA. Many counties have USDA service centers, housing the Natural Resources Conservation Service, the Farm Service Agency, Rural Development, and often county CES agents. Since counties are the typical organizational unit where information is sought and county agents have expressed the need for more long-term data, we developed a county-level dataset of projected midcentury temperature and precipitation for adaptation planning.

\section{Methods}

\subsection{Datasets}

\subsubsection{Historical climate data}

We used the 30-year normals data (1971-2000) from the PRISM Climate Group to represent historical temperature and precipitation (Daly et al. 2008). This is a baseline dataset describing average seasonal and annual maximum temperature ( $\mathrm{Tmax} ;{ }^{\circ} \mathrm{C}$ ), minimum temperature (Tmin; ${ }^{\circ} \mathrm{C}$ ), and total precipitation (ppt; mm). The normals dataset covers the contiguous US at an $800-\mathrm{m}(1 / 120$ th degree) spatial resolution. 


\subsubsection{Climate projection data}

We used statistically downscaled climate projections from 20 general circulation models (GCM) participating in the Coupled Model Inter-comparison Project 5 (CMIP5). The Multivariate Adaptive Constructed Analogs (MACA) downscaling approach (Abatzoglou 2013) was used as it has been shown to be able to better capture details of spatiotemporal variability in climate across the mountainous western US.

We specifically focus on midcentury (2040-2069) projections for the contiguous US using climate experiments run with forcing from Representative Concentration Pathway 8.5 (RCP 8.5). MACA downscales daily GCM fields of Tmax, Tmin, and ppt (among other variables), using a linear combination of historical spatial analogs for mapping GCM fields and an equidistant quantile mapping bias correction (Li et al. 2010; Pierce et al. 2015). We downloaded the MACAv2-METDATA monthly multi-model mean from 20 models of expected change between 1971 and 2000, representing historic PRISM and MACA, and 20402069 at the $4000-\mathrm{m}(1 / 24$ th degree) resolution.

\subsubsection{Historic data spatial resolution}

Both the 30-year 1971-2000 normals from PRISM (800 m) and MACA (4000 m) were considered to represent the historic condition. While the MACA data used a dataset that used PRISM time series data, they were produced at a coarser spatial resolution and correspond to model years (1971-2000) that may differ from observed normals slightly due to internal climate variability. We analyzed the difference in 1971-2000 annual and seasonal climate normals from the PRISM and MACA datasets (Online resource (OR) I). County-level historic data were strongly correlated $\left(R^{2}=0.971\right.$ to 0.9995$)$ despite the difference in original spatial resolution and internal climate variability. There were only nominal differences in county-level Tmax, Tmin, and precipitation (mean bias, Tmax $0.2{ }^{\circ} \mathrm{C}$, Tmin $0.3{ }^{\circ} \mathrm{C}$, precipitation $-1.1 \%$ ). This similarity was expected as both datasets use the same base data (PRISM) and the aggregation of these data to the county level largely negates any differences. Given the historic normal data similarity between PRISM and MACA, and the end-user familiarity with PRISM, we opted to use PRISM data as the normal background condition.

\subsection{Data processing and analysis}

To generate a historical baseline dataset, we used PRISM data to calculate a countylevel mean and standard deviation using ArcGIS and zonal statistics for seasonal and annual Tmax, Tmin, and ppt to represent "normal" historic conditions. Seasons were defined as winter (December-January-February), spring (March-April-May), summer (June-July-August), and fall (September-October-November). Next, we generated a second dataset (MACA) to represent the projected change for each county between the 2040-2069 and 1971-2000 time periods by using ArcGIS and zonal statistics to represent the change from historic conditions. Thus, means for historic conditions and future changes at the county level were developed discretely. We then summed the seasonal and annual average values from the corresponding multi-model mean to calculate the future values for each county. This approach of using downscaled data to estimate future change and apply the anticipated change to an alternate baseline 
dataset has precedent (Sofaer et al. 2017). We additionally calculated the standard deviation (SD) of mean changes among all 4-km pixels within each county, or the SD of the change data layer.

$\mathrm{SD}$ can be used as an estimate of the variability in the expected changes in Tmax, Tmin, and ppt across a county. SD represents the amount of variation in the pixel values comprising a county and is derived from the projected changes in Tmax, Tmin, and ppt, not future value projections, which are the sum of historic and projected change values. SD is used to evaluate the spatial variation in change. SD values closer to zero indicate a more spatially homogenous range of projected values and higher SD indicates more variability within the projected change. Users can use SD to decide if the average change in county values is sufficient to answer a specific question for their location, or if more spatially detailed information is warranted.

Results presented as average shifts in seasonal and annual conditions provide an estimate of future changes for scenario planning. However, we present only changes in mean climate distilled from 20 different GCM projections. This has advantages for some consumers as it avoids introducing the concepts of ensembles and uncertainties. In addition, the multi-model mean is often superior to any single model (Tebaldi and Knutti 2007). However, the full spread of projected changes in climate may be useful for more sophisticated consumers of information, particularly those which might want to devise adaptation strategies for a range of climate projections. Additionally, 30-year climatological summaries may help support dialog and planning, but may not sufficiently incorporate climatic extremes for scenario planning.

\section{Results and discussion}

\subsection{National county-level dataset summary}

National and regional maps and data are available as online resources supplemental to this article and at http://swclimatehub.info/data.

\subsubsection{Precipitation}

For most of the northern US, total precipitation is projected to increase and shift seasonally (OR II and III). Conversely, total precipitation is projected to decline across parts of the southern US. Declines in precipitation are most evident during the summer months across the nation.

In $92 \%$ of counties of the nation, the annual precipitation SD was less than $10 \mathrm{~mm}$, indicating that the change in midcentury precipitation varies by less than $10 \mathrm{~mm}$ across each county (OR IV). Counties with annual and seasonal precipitation SD larger than $10 \mathrm{~mm}$ were generally located in mountainous regions of the USA, particularly the Rocky Mountain and Appalachian regions. Nearly all eastern US counties had annual and seasonal precipitation SD less than $10 \mathrm{~mm}$. Based upon SD, seasonal and annual precipitation change for each county appears fairly homogenous for most of the USA suggesting projected changes in county precipitation values from the dataset could likely adequately represent mean county-level changes in most parts of the country. Projections of precipitation change in some counties of the Northwest, Northern Plains and Southwest Regions should be evaluated prior to applying changes uniformly across the counties. 


\subsubsection{Temperature}

Nationally, annual and seasonal mid-century Tmax (Fig. 2) and Tmin increase in all counties. The magnitude of the increase varies slightly by region and season. Annual Tmax increases are slightly higher for the Midwest and Northern Plains regions, and slightly lower in the Southeast region, with all regional increases ranging from 2.4 to $3.9^{\circ} \mathrm{C}$. Southeast, Southern Plains, and Southwest county summer median Tmax is near or higher than the thermal tolerance for some crops in certain counties (Hatfield et al. 2011; Luck et al. 2011). Increased Tmax in these regions may further limit production of certain crops. Future winter Tmin will increase most in the coldest counties $\left(+5^{\circ} \mathrm{C}\right)$ and less for warmer counties $\left(+2{ }^{\circ} \mathrm{C}\right)$. Increases in winter Tmin can adversely impact perennial crops with winter chilling requirements (Baldocchi and Wong 2008; Lobell and Field 2011) and snowpack accumulation. Conversely, warming of winter Tmin may allow for expansion of cold intolerant perennials (Parker and Abatzoglou 2016). Mean annual and seasonal anticipated changes provide a platform for evaluating and planning for both positive and negative potential impacts on specific commodities and ecosystems.

Tmax SD is less than $0.3{ }^{\circ} \mathrm{C}$ for all counties of the nation, indicating that the projected change in mean Tmax across counties is fairly spatially homogeneous. Most eastern counties have a lower annual and seasonal Tmax SD. The larger western counties located along the Pacific Coast have a wider ranging Tmax SD, with the largest Tmax SD occurring in summer. Tmin SD is also typically less than $0.3^{\circ} \mathrm{C}$. Most eastern counties have a low annual and seasonal Tmin SD, with the exception of some larger counties in Maine in winter. Winter Tmin SD was largest for some inland western counties whereas summer Tmin SD was largest for counties along the Pacific Coast. Given the low Tmax and Tmin SD $\left(<0.3^{\circ} \mathrm{C}\right)$ for mean annual and seasonal temperature changes in each county of the nation, compared to the daily variation in temperature at one location, the projected mean changes in temperature can be readily applied to counties nationwide. Data tables can be used (OR II) to estimate the $95 \%$ range of pixels comprising county values as the mean $\pm 2 \mathrm{SD}$.

\subsection{Regional summaries}

\subsubsection{Midwestern region}

In the Midwest (MW), corn and soybean production occur on $75 \%$ of the arable land. Precipitation is projected to increase in fall, winter, and spring and decrease in summer. The increase in spring precipitation may reduce the number of workable field days and disrupt planting operations in the region (Hatfield et al. 2015). The median annual increase in county precipitation in the MW is projected to be $64 \mathrm{~mm}$, mostly occurring in the winter and spring. The maximum annual ppt change SD of all the counties in the MW is $15.2 \mathrm{~mm}$, suggesting relatively homogenous county-level precipitation change.

The average annual county-level increase in midcentury Tmax in the $\mathrm{MW}$ is $3.5^{\circ} \mathrm{C}$, with the highest average increase $\left(4.0^{\circ} \mathrm{C}\right)$ in summer. The average annual county-level increase in Tmin is $3.4^{\circ} \mathrm{C}$, with the maximum increase in Tmin $\left(5.3^{\circ} \mathrm{C}\right)$ occurring in winter. The largest county-level Tmax or Tmin SD is $0.07^{\circ} \mathrm{C}$, indicating small temperature variation in projected changes. Warmer temperatures in the MW create the potential for more overwintering of insects (Hatfield et al. 2015) and the advancement in the timing of spring greenup with warming may increase the potential for spring freeze events (Allstadt et al. 2015). 

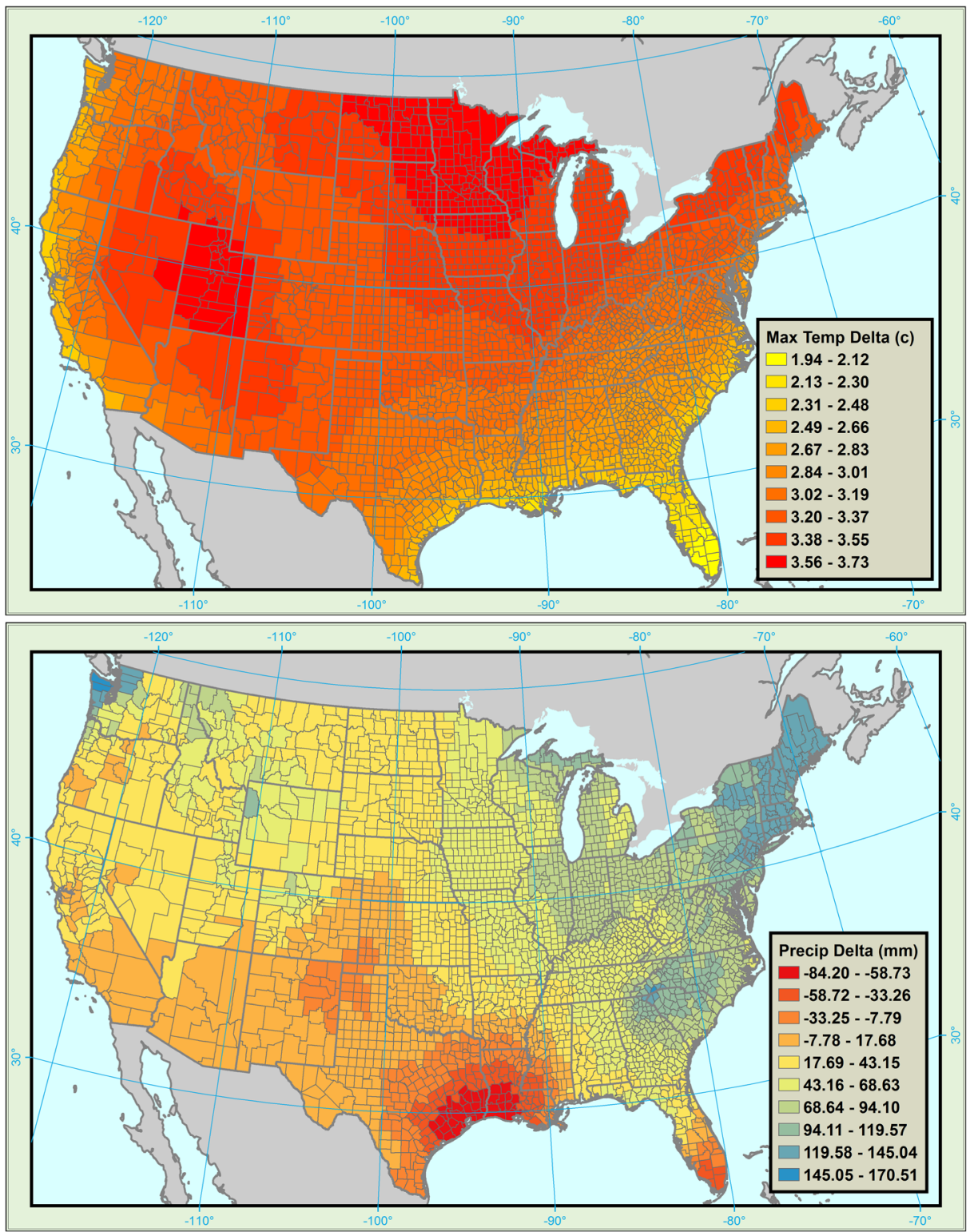

Fig. 2 Example of county-level change in mid-century precipitation and maximum temperature comparing 1971-2000 to 2040-2069 projections using the representative concentration pathway 8.5 downscaled data. Regional and seasonal maps for maximum temperature, minimum temperature, and precipitation provided in Online resource II and at (http://swclimatehub.info/data)

\subsubsection{Northeastern region}

Despite the densely populated area, the Northeast (NE) region contains significant timberland and farmland. County-level annual and seasonal precipitation increase in nearly all counties of the NE. Wet springs are already delaying planting and harvesting dates and reducing crop 
yields (Tobin et al. 2015). The annual average increase in county precipitation in the NE is $103 \mathrm{~mm}$, mostly falling in winter $(39 \mathrm{~mm})$ and spring $(33 \mathrm{~mm})$ and expected to further challenge regional crop production. The largest SD in county-wide annual precipitation change across the NE is $21.4 \mathrm{~mm}$.

The average annual increase in Tmax and Tmin in NE counties is $3.2^{\circ} \mathrm{C}$, with the largest increase in Tmax in summer $\left(3.7^{\circ} \mathrm{C}\right)$ and the largest increase in Tmin in winter $\left(4.9^{\circ} \mathrm{C}\right)$. The maximum annual and seasonal county SD for $\operatorname{Tmax}\left(<0.08^{\circ} \mathrm{C}\right)$ and $\operatorname{Tmin}\left(<0.20{ }^{\circ} \mathrm{C}\right)$ indicate small variation in temperature change projections across NE counties.

\subsubsection{Northwestern region}

Nearly a quarter of the land in the Northwest (NW) region is used for agricultural production, supplying half the nation's potato crop and $70 \%$ of the nation's apples. Total annual precipitation increases in all NW counties, whereas summer precipitation decreases in three-fourths of NW counties. Spring and fall precipitation increase in $90 \%$ of the regions' counties. Increased rainfall in the region can impact fruits, tree nuts, and berries via increased fungal pathogens and rain cracking, characterized by splitting in the outside layer of the cuticle (Creighton et al. 2015). Conversely, increased cool season precipitation, warmer temperatures, and elevated $\mathrm{CO}_{2}$ may be beneficial for rainfed winter crops such as winter wheat that can capitalize on an earlier start to the growing season when soil water is more available (Stöckle et al. 2010). Reduced mountain snowpack and the lack of water management infrastructure may impact irrigated crop production in the NW as more runoff is projected to occur during the winter and spring and less during the summer months when irrigation is required (Fritze et al. 2011; Mote et al. 2005). The NW has a relatively large annual precipitation SD with only $36 \%$ of counties with an SD of less than $10 \mathrm{~mm}$, but all counties with an SD of less than $80 \mathrm{~mm}$. This indicates that the projected changes in precipitation can vary widely across NW counties, likely consistent with the present high and variable county-level precipitation. Use of NW county-level ppt projections should be evaluated on a seasonal, county, and application basis.

Annual average increase in NW Tmax and Tmin are approximately $3.0^{\circ} \mathrm{C}$. The maximum temperature change $\mathrm{SD}$ across $\mathrm{NW}$ counties is less than $0.26^{\circ} \mathrm{C}$, with the highest $\mathrm{SD}$ in summer.

\subsubsection{Northern plains region}

The northern plains (NP) region, containing more than one-third of the nation's rangeland, is expected to undergo seasonal shifts in precipitation. Annual and winter precipitation is projected to increase in nearly all NP counties. In contrast, summer precipitation decreases in $88 \%$ of NP counties, influencing availability of water for producers and municipalities (Derner et al. 2015). The highest annual ppt change SD for NP counties (Glacier County, MT) is $53.1 \mathrm{~mm}$. NP winter and spring ppt have counties with larger $(>20 \mathrm{~mm}) \mathrm{SD}$ whereas all counties have lower summer SD $(<4 \mathrm{~mm})$. Use of NP county-level ppt projections should be evaluated on a county basis, particularly in winter and spring where deviation of $>20 \mathrm{~mm}$ across a county may have resource management implications.

Annual average increases in midcentury NP county-level Tmax and Tmin are approximately $3.4{ }^{\circ} \mathrm{C}$ with the largest increases in summer for Tmax $\left(4.1{ }^{\circ} \mathrm{C}\right)$ and winter for Tmin $\left(5.3^{\circ} \mathrm{C}\right)$. Longer and warmer growing seasons in the NP can alter pest and weed pressure and reduce livestock carrying capacity by favoring non-native, invasive plant expansion (Derner et al. 2015). 


\subsubsection{Southeastern region}

The Southeastern (SE) region produces much of the nation's timber and pulp wood supplies along with cotton, peanuts, citrus, and specialty crops. Reduced regional farm and forest productivity may result from altered rainfall patterns and increasing climate variability (McNulty et al. 2015). Annual precipitation is projected to increase in $88 \%$ of SE counties, whereas summer precipitation is projected to decline in half of SE counties, mostly located in south Florida and southwestern Mississippi and Louisiana. The annual maximum ppt change SD of the 1009 counties comprising the SE region is $31 \mathrm{~mm}$, with each season/county combination showing a county-wide SD of $<10 \mathrm{~mm}$, indicating little variance in ppt projections within SE counties. Both drought and excessive water are listed as vulnerabilities for crops common to the region including cotton, corn, rice, wheat, minor grains, and strawberries.

Midcentury annual mean county-level temperatures increase in the SE, with the largest increases occurring in the summer $\left(\operatorname{Tmax} 4.1{ }^{\circ} \mathrm{C}\right.$; Tmin $\left.3.4^{\circ} \mathrm{C}\right)$. Rising temperatures in the SE may increase the risk of heat stress for crops and increase production costs (McNulty et al. 2015).

\subsubsection{Southern Plains region}

The Southern Plains (SP) region contributes substantially to the nation's wheat and beef production. Over half SP counties are projected to have a decrease in annual precipitation by midcentury. While the decline is most evident in summer, with $93 \%$ of SP counties showing a precipitation decline, county precipitation declines are also evident in other seasons. SP ppt change SD is low, with annual $(<7.8 \mathrm{~mm})$ and seasonal $(<4.4 \mathrm{~mm})$ values indicating low variability in county-level ppt change. Reduced precipitation may make the region more prone to drought thereby reducing production and economic viability, increasing reliance on groundwater and further reducing Ogallala Aquifer levels (Steiner et al. 2015).

SP annual mean county-level Tmax and Tmin are projected to increase 3.1 and $2.9^{\circ} \mathrm{C}$, respectively, with the largest increase occurring in summer. Increased temperatures in the SPmay increase vulnerability to late season frost, pest pressure and heat stress (Steiner et al. 2015).

\subsubsection{Southwestern region}

Unlike other regions of the USA, where a decline in precipitation is most evident during the summer months, precipitation declines in southwestern (SW) counties are most evident in spring with $69 \%$ of counties exhibiting a decline in projected spring precipitation. Declines in spring precipitation lead to drier conditions during planting of corn, cotton, spring barley, and other regional crops (Elias et al. 2015). The largest SW annual ppt change SD is $24.2 \mathrm{~mm}$, but most annual ppt change SD in the SW is $<10 \mathrm{~mm}$. Winter ppt change SD is high in several SW counties, located in California and Utah, whereas fall, spring and summer SD are $<10 \mathrm{~mm}$ in all SW counties.

Mean annual Tmax and Tmin across SW counties is projected to increase by 3.2 and $2.9^{\circ} \mathrm{C}$, respectively. The highest increase in Tmax $\left(4.0^{\circ} \mathrm{C}\right)$ occurs in summer, whereas the highest increase in $\mathrm{Tmin}\left(4.1^{\circ} \mathrm{C}\right)$ occurs in winter. The SW contains several counties, mostly 
in central CA, with the largest national annual and seasonal temperature SD. While Fresno County in California consistently has the largest Tmax SD, it still represents a relatively small value $\left(0.3{ }^{\circ} \mathrm{C}\right)$ indicating that projected temperature changes vary minimally across counties and are likely less important than ppt SD values.

\subsection{Data access via web-based decision support tool}

Annual and seasonal precipitation and temperature data for the historical period, change between historical and future, and future period are provided by county (USDA Southwest Climate Hub 2016). National and regional static and interactive maps of Tmax, Tmin, ppt, and SD by season are provided online (http://swclimatehub.info/data) and as a supplement to this submission. Agricultural advisors can access county-level data tables for Tmax, Tmin, ppt, and SD online, as well as boxplots of regional differences. To access data via the interactive map showing historic (1971-2000) and future (2040-2069) data and graphs, users select the variable and county of interest. Users can also download data for each region and export it to an external table.

\section{Data use examples in working-lands decision-making}

Midcentury county-level data from our dataset are used to estimate the impact of climate change on forage and almond production as example applications useful to farm and forest advisors supplying grower information at the county level.

\subsection{Rangeland}

County-level precipitation can be used to estimate future forage production. We downloaded historic and future precipitation by season to use in a New Mexico Drought calculator (http://arsagsoftware.ars.usda.gov) (U.S. Department of Agriculture Agricultural Research Service 2015). The Drought Calculator (DC) was developed to help farmers and ranchers predict reductions in forage production due to drought for 11 western states. The DC is most useful in giving a quantitative prediction of forage growth potential (Dunn et al. 2013). For this example, we used the New Mexico Drought calculator with historic and predicted precipitation for Otero County, New Mexico to estimate changes in forage production. Changes in seasonal precipitation are projected for the region with decreases during the winter and spring. To estimate the projected impact on forage yield potential under future changes in climate, we applied projected changes in precipitation to observed data from a recent drought year (2012). We used measured precipitation of southern New Mexico from the most recent drought year (2012) downloaded from the National Climatic Data Center for New Mexico Climate Division 8 (Southern Desert) (NOAA 2015). We then applied the projected seasonal precipitation changes from our dataset for Otero County. In this application, the forage yield potential is reduced to $58 \%$ from the 2012 values based upon Climate Division 8 precipitation, with consistently lower potential throughout the year. The county mid-century data thus provides an estimate to Otero County ranchers of the impact of a future drought year on forage production. The quick estimate reported here could be refined by using weather station data and other information for scenario analyses with producers. 


\subsection{Perennial crops}

The county-level increase in winter Tmin can be used to estimate the impact on nut and stone-fruit crops to meet minimum chill requirements. Researchers have reported almond crops may reach insufficient winter chilling hours in California (Lobell and Field 2011). In 2014, Kern County grew the largest almond acreage in California (California Department of Food and Agriculture 2015). We use hourly measured temperature (2011 to 2015) from Belridge, California weather station, which is part of the California Irrigation Management Information System network, has a consistent record with few missing values and is located near almond orchards and the dynamic model, which measures chill portions, to calculate historical chill portions. To estimate midcentury chill portions, the predicted seasonal increases in Tmin for Kern County were added to the hourly temperature data and applied in the dynamic model. Of the 5 years simulated with midcentury Tmin, none decreased below the minimum chill portion requirement for nonpareil almonds (23 portions), but 1 year decreased to near chill portion requirement (26 portions), indicating a possible lack of sufficient chill portions to sustain almond production in one of 5 years in Kern County in future (Pope 2015). Knowledge of midcentury temperature projections near the chill portion requirement for nonpareil almonds in certain years could support adaptation planning, including almond variety selection and adaptation planning.

\subsection{Specialty and field crops}

Two articles of this issue rely upon the county-level data to project impacts of future heat stress at the county level on specialty crops in California (Kerr et al., this issue) and regional field crops (Elias et al., this issue).

\section{Conclusions}

The data tool described here provides an expected mean change in seasonal and annual conditions to support county-level discussions between stakeholders and service providers. While mean seasonal and annual data do not support all management decisions, since natural variability and extremes remain a key determinant of annual success in most agricultural enterprises, the online data tool can provide a rapid indication of expected average changes.

County-level data show regional differences in anticipated changes in Tmax, Tmin, and ppt. While temperatures are projected to increase across all counties, counties of certain regions are projected to increase more than other regions. For example, the SE has lower projected change in annual Tmax $\left(2-3{ }^{\circ} \mathrm{C}\right)$ than the MW $\left(>3.5^{\circ} \mathrm{C}\right)$. Increases in winter Tmin are higher for MW and NP counties (up to $5.3^{\circ} \mathrm{C}$ ) than those of the SE and SW (near $2.0^{\circ} \mathrm{C}$ ). Tmax and Tmin SD for all counties was less than $0.3{ }^{\circ} \mathrm{C}$ indicating that projected changes in temperature are fairly homogenous within counties. Regional precipitation changes have varied impacts. For example NE ppt is projected to increase in all seasons impacting planting and harvesting. In contrast, summer ppt is projected to decrease in many MW, NW, NP, and SP counties, which may be helpful to agricultural operations in certain areas, but hinder operations in arid regions. Supplying the county SD allows for data users to decide an acceptable variation in projected temperature or precipitation change across a selected county to indicate if use of localized data is warranted. Applications of the 
county-level data tool include informing farm advisor discussions about projected changes, scenario planning for decision-makers, foundational data for educational programs, such as the SW Climate Hub 'Climate Change and the Hydrologic Cycle' unit (http://www.swclimatehub. info/education/climate-change-and-water-cycle) and research applications.

While the difference in county size could have important implications for the direct utility of the county climatic projections by region, these differences were not large enough to influence the use of county-level projections of change in Tmax and Tmin, which showed the largest Tmax and Tmin SD as $0.3^{\circ} \mathrm{C}$. Larger counties, such as those across the western US, may span a range of latitudes and elevations resulting in diverse climates at sub-county levels; however, changes in mean seasonal and annual temperatures from the county-level dataset can be readily used. Heterogeneity in temperature and precipitation is evident for counties with substantial topographic variability, including much of the western half of the country, possibly rendering county-level precipitation projections less certain when applied county-wide. Annual precipitation SD shows counties of mountainous regions, particularly in the western US, with higher SD possibly necessitating the use of finer-scale spatial data, depending upon the agricultural management issue to be addressed.

The choice of RCP 8.5 represents the scenario with the highest greenhouse gas emissions indicating potentially large local changes in temperature and precipitation that would impact agricultural and natural resource management operations. This encourages consideration of the potential impacts to operations under likely future conditions and supports conversations on management actions that can be taken today to mitigate future risks (e.g., orchard tree selections, long-term forest management plans, and creative options in support of adaptation) and build resilience in agricultural and natural resources operations. The national variability in present and anticipated changes, along with the resultant variation in regional and local working lands, necessitates the use of county-level or finer-scale projections of future changes to support conversations at a local level between agricultural advisors and farmers, ranchers and foresters to build resilient and adaptable communities. Data use examples of county forage production, almond chilling portions, and crop vulnerability provide examples of rapid, county-level analyses available to advisors based upon county-level data.

Acknowledgements This work is a contribution of the Southwest Region Climate Hub of the United States Department of Agriculture (USDA) Risk Adaptation and Mitigation to Climate Change Network. Manuscript development was supported by the USDA, Agricultural Research Service, Rangeland Management Research Unit based at the Jornada Experimental Range with funding by the USDA (CRIS Project \# 3050-11210-007D) and the National Science Foundation (Grant DEB-0618210). Thanks to Danielle Shannon and Ryann Smith.

Open Access This article is distributed under the terms of the Creative Commons Attribution 4.0 International License (http:/creativecommons.org/licenses/by/4.0/), which permits unrestricted use, distribution, and reproduction in any medium, provided you give appropriate credit to the original author(s) and the source, provide a link to the Creative Commons license, and indicate if changes were made.

\section{References}

Abatzoglou JT (2013) Development of gridded surface meteorological data for ecological applications and modelling. Int J Climatol 33:121-131

Allstadt AJ, Vavrus SJ, Heglund PJ, Pidgeon AM, Thogmartin WE, Radeloff VC (2015) Spring plant phenology and false springs in the conterminous US during the 21st century. Environ Res Lett 10:104008

Anderson CJ, Babcock BA, Peng Y, Gassman PW, Campbell TD (2015) Placing bounds on extreme temperature response of maize. Environ Res Lett 10:124001 
Anyamba A, and et al. (2014) Recent weather extremes and impacts on agricultural production and vector-borne disease outbreak patterns. PloS one, 9

Baldocchi D, Wong S (2008) Accumulated winter chill is decreasing in the fruit growing regions of California. Clim Chang 87:153-166

Brugger J, Crimmins M (2014) Designing institutions to support local-level climate change adaptation: insights from a case study of the U.S. cooperative extension system. Weather, Climate, and Society 7:18-38

California Department of Food and Agriculture, 2015: 2014 California almond acreage report

Cash DW (2001) In order to aid in diffusing usefule adn practical information: agricultural extension and boundary organizations. Science, Technology, and Human Values 26:431-453

Creighton J, and et al. (2015) Northwest regional climate hub assessment of climate change vulnerability and adaptation and mitigation strategies

Daly C et al (2008) Physiographically-sensitive mapping of temperature and precipitation across the conterminous United States. Int J Climatol 28:2031-2064

Derner J, Joyce L, Guerrero R, and Steele R (2015) USDA Northern Plains regional climate hub assessment of climate change vulnerability and adaptation and mitigation strategies

Deryng D, Conway D, Ramankutty N, Price J, Warren R (2014) Global crop yield response to extreme heat stress under multiple climate change futures. Environ Res Lett 9

Dunn GH, Gutwein M, Green TR, Menger A, Printz J (2013) The drought calculator: decision support tool for predicting forage growth during drought. Rangel Ecol Manag 66:570-578

Duveneck MJ, Scheller RM (2015) Climate-suitable planting as a strategy for maintaining forest productivity and functional diversity. Ecol Appl 25:1653-1668

Elias EH, and et al. (2015) Southwest regional climate hub and California subsidiary hub assessment of climate change vulnerability and adaptation and mitigation strategies. U.S. Department of Agriculture, Ed., 76

Fiebrich CA (2009) History of surface weather observations in the United States. Earth Sci Rev 93:77-84

Fritze H, Stewart IT, Pebesma E (2011) Shifts in western North American snowmelt runoff regimes for the recent warm decades. J Hydrometeorol 12:989-1006

Fuglie K, MacDonald J, and Ball E (2007) Productivity growth in U.S. agriculture, 7 pp.

Hatfield J et al (2011) Climate impacts on agriculture: implications for crop production. Agron J 103:351-370

Hatfield J, and et al. (2015) USDA midwest and northern forests regional climate hub: assessment of climate change vulnerability and adaptation and mitigation strategies, $55 \mathrm{pp}$.

Lazo JK, Lawson M, Larsen PH, Waldman DM (2011) U.S. economic sensitivity to weather variability. Bull Am Meteorol Soc 92:709-720

Li H, Sheffield J, and Wood EF, (2010) Bias correction of monthly precipitation and temperature fields from Intergovernmental Panel on Climate Change AR4 models using equidistant quantile matching. J Geophys Res, 115

Lobell DB, Field CB (2011) California perennial crops in a changing climate. Clim Chang 109:317-333

Luck J, Spackman M, Freeman A, Tre bicki P, Griffiths W, Finlay K, Chakraborty S (2011) Climate change and diseases of food crops. Plant Pathol 60:113-121

Luedeling E, Zhang M, Girvetz EH (2009) Climatic changes lead to declining winter chill for fruit and nut trees in California during. PLoS One 4:1950-2099

McNulty S, and et al. (2015) Southeast regional climate hub assessment of climate change vulnerability and adaptation and mitigation strategies

Menne MJ, Durre I, Vose RS, Gleason BE, Houston TG (2012) An overview of the global historical climatology network-daily database. J Atmos Ocean Technol 29:897-910

Mote PW, Hamlet AF, Clark MP, Lettenmaier DP (2005) Declining mountain snowpack in western North America*. Bull Am Meteorol Soc 86:39-49

NOAA (2015) Climate at a glance. N. C. f. E. Information, Ed

Parker LE, Abatzoglou JT (2016) Projected changes in cold hardiness zones and suitable overwinter ranges of perennial crops over the United States. Environ Res Lett 11:034001

Pierce DW, Cayan DR, Maurer EP, Abatzoglou JT, Hegewisch KC (2015) Improved bias correction techniques for hydrological simulations of climate change*. J Hydrometeorol 16:2421-2442

Pope K (2015) Chilling requirements in chill portions for California crops. The Almond Doctor, University of California Cooperative Extension

Prokopy LS et al (2015) Extension's role in disseminating information about climate change to agricultural stakeholders in the United States. Clim Chang 130:261-272

Schauberger B et al (2017) Consistent negative response of US crops to high temperatures in observations and crop models. Nat Commun 8:13931

Sofaer HR, Barsugli JJ, Jarnevich CS, Abatzoglou JT, Talbert MK, Miller BW, and Morisette JT (2017) Designing ecological climate change impact assessments to reflect key climatic drivers. Global Change Biology, n/a-n/a 
Solís D, Letson D (2013) Assessing the value of climate information and forecasts for the agricultural sector in the southeastern United States: multi-output stochastic frontier approach. Reg Environ Chang 13:5-14

Steiner JL, Schneider JM, Pope C, Pope S, Ford P, and Steele R, (2015) Southern Plains assessment of vulnerability and preliminary adaptation and mitigation strategies for farmers, Ranchers, and Forest Land Owners

Stöckle CO et al (2010) Assessment of climate change impact on eastern Washington agriculture. Clim Chang 102:77-102

Tebaldi C, Knutti R (2007) The use of the multi-model ensemble in probabilistic climate projections. Phil Trans R Soc 365:2053-2075

Tobin D, and et al. (2015) Northeast and northern forests regional climate hub assessment of climate change vulnerability and adaptation and mitigation strategies

U.S. Department of Agriculture Agricultural Research Service, 2015

USDA Southwest Climate Hub, cited 2016: County level temperature and precipitation maps. [Available online at http://swclimatehub.info/data]

Walthall CL, and et al. (2012) Climate change and agriculture in the US: effects and adaptation. elec 1935, 186pp pp.

Williams MI, Dumroese RK (2013) Preparing for climate change: forestry and assisted migration. J For 111:287297 